\title{
PENGEMBANGAN WISATA PANTAI WAMSOBA BERBASIS KEARIFAN LOKAL DI KABUPATEN BURU SELATAN PROVINSI MALUKU
}

\author{
Oleh \\ Ashari Tomia ${ }^{1}$, \\ Etin Indrayani ${ }^{2}$, Romi Saputra ${ }^{3}$ \\ ${ }^{1)}$ Pemerintah Daerah Kabupaten Buru Selatan \\ Program Magister Terapan Studi Pemerintahan Daerah Institut Pemerintahan Dalam Negeri \\ ashari030193@gmail.com \\ 2,3) Institut Pemerintahan Dalam Negeri
}

\section{ABSTRACT \\ DEVELOPMENT OF WAMSOBA BEACH TOURISM BASED ON LOCAL CULTURE IN BURU SELATAN REGENCY, MALUKU PROVINCE}

$T$

he tourism development program based on local wisdom of Wamsoba Beach is expected to contribute to economic development. Buru Selatan Regency is a paradise for divers. One of them is Maluku City, which is not only beautiful in nature but also beautiful under the sea. The purpose of this study is to determine tourism development, determine the factors that influence tourism development, and know the strategies carried out by the Wamsoba Coastal Culture and Tourism Office based on local wisdom in Buru Selatan Regency;

The method used is a qualitative research method with a case study approach. Sources of data needed in the form of primary, secondary data sources, and informant selection. primary data sources obtained from the results of interviews and observations, while secondary data sources obtained from documentation in the form of books, documents and regulations. Informants were determined by purposive sampling as many as 15 people. Data collection instruments using interview guidelines refers to the concept or theory of tourism development by Alister Matchieoson and Geoffrey Wall as quoted in Sunaryo (2013: 53-54).The data analysis technique used the SWOT method with the stages of data collection, data condensation, data presentation, and drawing conclusions (verification);

The results showed that the implementation of tourism development based on local wisdom in the Buru Selatan regency of Maluku province still needs to be developed becomes one of the leading regional tourism objects in the Buru Selatan Regency. This can be seen from the lack of public concern to preserve the value of local wisdom in the tourist area, facilities. public infrastructure and tourist services. The supporting factors for the development of local wisdom-based tourism in the Buru Selatan regency of Maluku province are 1). Determine the zoning of tourism destination locations for, local, national and international by mapping tourist objects and making maps/routes of tourist areas, 2). Development of tourist attractions (tourist attractions). 3). Public infrastructure, public facilities and tourism and 4). Community empowerment includes tourism awareness and community capacity building. The strategy carried out in the context of developing local wisdom-based tourism in the Buru Selatan regency of Maluku province includes 
components that will contribute to the success of a tourist destination in particular and tourism in general, including marketing, institutionalization and the tourism industry

Keywords: local wisdom, tourism development

\begin{abstract}
AbSTRAK
Program pengembangan wisata berbasis kearifan lokal Pantai Wamsoba diharapkan dapat memberikan sumbangan bagi pembangunan ekonomi.Kabupaten Buru Selatan adalah salah satu surga bagi divers. Salah satunya adalah Kota Maluku, yang tidak hanya indah alamnya tetapi juga indah pemandangan bawah lautnya. Tujuan penelitian ini adalah Untuk mengetahui pengembangan wisata, mengetahui faktor-faktor yang memengaruhi pengembangan wisata, dan mengetahui strategi yang dilakukan Dinas Kebudayaan dan Pariwisata Pantai Wamsoba berbasis kearifan lokal di Kabupaten Buru Selatan Provinsi Maluku;

Metode yang digunakan adalah metode penelitian kualitatif dengan pendekatan studi kasus. Sumber data yang diperlukan berupa sumber data primer sekunder dan pemilihan informan, sumber data primer diperoleh dari hasil wawancara dan observasi, sedangkan sumber data sekunder diperoleh dari dokumentasi berupa buku-buku, dokumen-dokumen dan peraturan-peraturan. Informan ditentukan melalui purposive sampling sebanyak 15 orang. Instrumen pengumpulan data menggunakan pedoman wawancara mengacu pada konsep atau teori tentang pengembangan wisata Alister Matchieoson dan Geoffrey Wall yang dikutip dalam Sunaryo (2013: 53-54),.Teknik analisis data menggunakan metode SWOT dengan tahapan pengumpulan data, kondensasi data, penyajian data, dan penarikan simpulan (verifikasi);

Hasil penelitian menunjukkan bahwa pelaksanaan pengembangan wisata berbasis kearifan lokal di Kabupaten Buru Selatan Provinsi Maluku Masih perlu dikembangkan agar menjadi salah satu objek wisata unggulan daerah di Kabupaten Buru Selatan, Hal ini terlihat dari kurangnya kepedulian masyarakat untuk menjaga kelestarian nilai kearifan lokal di kawasan wisata, fasilitas prasarana umum dan pelayanan wisatawan. Faktor-faktor pendukung pengembangan wisata berbasis kearifan lokal di Kabupaten Buru Selatan Provinsi Maluku di antaranya adalah 1). Menentukan perwilayahan lokasi destinasi pariwisata untuk, lokal, nasional dan internasional dengan melalui pemetaan objek wisata dan membuat peta/jalur kawasan wisata, 2). Pembangunan daya tarik wisata (Atraksi wisata). 3). Prasarana umum, fasilitas umum dan pariwisata dan 4). Pemberdayaan masyarakat meliputi sadar wisata dan pengembangan kapasitas masyarakat. Strategi yang dilakukan dalam rangka pengembangan wisata berbasis kearifan lokal di Kabupaten Buru Selatan Provinsi Maluku mencakup komponen-komponen yang akan berkontribusi pada keberhasilan suatu destinasi wisata secara khusus dan kepariwisataan secara umum, baik meliputi pemasaran, kelembagaan dan industri pariwisata.
\end{abstract}

Kata kunci: kearifan lokal, pengembangan wisata

\section{PENDAHULUAN}

Sektor pariwisata merupakan salah satu Ssektor penting dalam perekonomian, Pemerintah dalam hal ini sebagai pemangku kebijakan telah membuat terobosan dengan mulai membuat kebijakan pada bidang pariwisata berupa pembuatan undang-undang, keputusan presiden, keputusan menteri, dan peraturan daerah. Pentingnya sektor pariwisata dalam perekonomian Indonesia, maka pengembangan pariwisata harus dilakukan melalui berbagai pendekatan sistem, yang terpadu, utuh dan partisipatoris. Namun demikian tidak lepas dari kriteria keekonomian, kriteria teknis, aspek sosial budaya, kelestarian dan lingkungan.

Pada 2018, pemerintah menempatkan pariwisata sebagai sektor unggulan 
pembangunan (Sumber: Strategi Pengembangan Kepariwisataan, Kemenpar 2019). Performa kepariwisataan Indonesia pada 2017 meningkat, hal ini terlihat dari dinobatkan Indonesia sebagai "Indonesia is in top-20 fastest growing travel destination in the world" (Telegraph, 2017). Pada yang sama, Indonesia memiliki pertumbuhan kunjungan tiga kali lebih besar dari pertumbuhan regional dan global (Sumber: Statistik eac country, Kemenpar 2019).

Penerimaan devisa dari sektor Pariwisata cenderung meningkat dari tahun 2015 sampai dengan 2019, serta diproyeksikan pada 2020 mencapai lebih dari 20 miliar USD.

\section{Identifikasi Masalah}

Berdasarkan latar belakang tersebut di atas, penulis dapat identifikasi beberapa permasalahan sebagai berikut.

1. Kondisi fisik Pantai Wamsoba kotor, ketersediaan tempat sampah terbatas, tidak ada petugas kebersihan, tata letak bangunan tidak efektif;

2. Sarana dan prasarana pendukung pariwisata belum memadai seperti tempat parkir, musala, toilet;

3. Aksesibilitas cukup sulit, karena belum ada sarana angkutan dan belum ada bus pariwisata yang menghubungkan masing-masing objek wisata di Kabupaten Buru Selatan;

4. Kunjungan wisatawan mancanegara mengalami penurunan;

5. Sarana dan prasarana hotel atau penginapan kurang memadai;

6. Kontribusi wisata terhadap Pendapatan Asli Daerah masih belum optimal;

\section{KAJIAN PUSTAKA}

\section{Tinjauan Hasil Penelitian Terdahulu}

Hasil penelitian terdahulu sangat penting dalam memperkaya teori dan praktis penelitian, sumber penelitian terdahulu dalam penelitian ini berasal dari lima penelitian luar negeri dan lima penelitian dalam negeri. Untuk lebih jelasnya sebagai berikut.

1. Rapanna, Patta, 2018.

Telah melakukan penelitian dengan judul "The Development of Tourism Based on Local Wisdom in Indonesia". Metode yang digunakan dalam penelitiannya adalah kualitatif pendekatan fenomologis. Hasil penelitian menunjukkan bahwa Pariwisata di Indonesia baru-baru ini dikembangkan dalam berbagai dimensi tujuan seperti wisata alam/ wisata bahari, budaya (berwujud: situs, bangunan keagamaan, kuil, bangunan bersejarah, bangunan tradisional, museum; tidak berwujud: bea cukai, nilai budaya), wisata kuliner, wisata olahraga, wisata kesehatan, pendidikan pariwisata, wisata agro, pariwisata, wisata religius, dll, untuk itu diperlukan pengembangan kebijakan pariwisata mendukung berbagai komponen, yaitu unsur-unsur pemerintahan, sektor swasta, akademisi dan publik pada umumnya.

2. Urapree Prapasawasdi, Lunchakorn Wuttisittikulkij, Chaleeda Borompichaichartkul, Laphasrada Changkaew. 2018.

Urapree Prapasawasdi dkk. dengan judul "Cultural Tourism Behaviors: Enhancing the Influence of Tourists' Perceptions on Local Thai Food and Culture". Perilaku wisatawan memainkan peran utama dalam melestarikan warisan budaya dan mendukung ekonomi masyarakat setempat. Makanan lokal merupakan faktor penting bagi wisatawan dan aspek budaya penting yang membedakan satu negara dari satu negara ke negara lain. Untuk memahami pengambilan keputusan tentang makanan wisatawan, penelitian ini menyelidiki persepsi wisatawan tentang makanan lokal. 
Metodologi campuran menggunakan strategi transformatif bersamaan. Penelitian kualitatif terdiri dari wawancara mendalam yang dilakukan dengan lima belas spesialis makanan lokal dan sepuluh wisatawan; kuantitatif terdiri dari survei terstruktur kuesioner dengan sampel empat ratus wisatawan bepergian di Chiangmai, Thailand. Hasil penelitian menunjukkan bahwa persepsi wisatawan yang terdiri dari sikap, norma subjek, nilai yang dipersepsikan dan faktor harapan secara positif memengaruhi persepsi terhadap informasi makanan lokal. Analisis regresi menunjukkan bahwa keempat variabel berkontribusi 53,4\% terhadap variasi makanan lokal. Dengan menggunakan koefisien standar seperti yang disebutkan, model regresi linier adalah $\mathrm{Y}=0,424 \mathrm{~A}-0,201 \mathrm{~S}+0,428 \mathrm{E}+0,234 \mathrm{P}$.

Empat faktor yang memengaruhi persepsi wisatawan terhadap makanan lokal sebagai berikut: (1) harapan terhadap informasi makanan lokal melalui media, (2) sikap wisatawan terhadap makanan lokal, (3) persepsi nilai makanan lokal dengan manfaat, kepercayaan dan nutrisi lokal makanan, dan (4) norma subjek terhadap makanan lokal; Pakar makanan lokal berpengaruh terhadap wisatawan. Semua faktor membuat wisatawan memahami makanan dan budaya setempat.

\section{Konsep Perencanaan dan Strategi Pengembangan Wisata}

Pembangunan kepariwisataan pada umumnya diarahkan sebagai sektor andalan dan unggulan untuk mendorong pertumbuhan ekonomi, meningkatkan pendapatan daerah, memberdayakan perekonomian masyarakat, memperluas lapangan kerja dan kesempatan berusaha, serta meningkatkan kesejahteraan rakyat dengan tetap memelihara kepribadian bangsa, nilai-nilai agama, serta kelestarian fungsi dan mutu lingkungan hidup.
Melihatbetapa pentingnyaperan industri pariwisata, maka kebijakan pemerintah dalam pengembangan wisata diharapkan dapat memberikan dampak positif bagi kehidupan sosial ekonomi masyarakat lokal. Menurut Goeldner R, Ritchie B.R.J; Mc Intosh W.R (2000) tourism policy adalah:

Suatu kelompok peraturan,
ketentuan, tujuan dan strategi untuk
pengembangan/promosi, r yang
menyediakan suatu kerangka untuk
mengambil keputusan secara kolektif
dan individual yang memengaruhi
pengembangan pariwisatar secara
langsung, serta aktivitas harian dalam
suatu destinasi.

\section{METODE PENELITIAN}

Penelitian diartikan sebagai suatu rangkaian kegiatan ilmiah yang dilakukan dengan secara sistematis, metodologis dan konsisten serta bertujuan untuk mengungkap kebenaran. Rangkaian ini didasarkan pada analisis dan konstruksi logis, sehingga menjadi salah satu manifestasi dari keinginan manusia apa yang sedang dihadapinya. Menurut Indrawan dan Yaniawati, (2014: 51), menyatakan bahwa penentuan metode mana yang dipilih, ditentukan oleh tiga hal, yakni (a) karakteristik keilmuan, (b) sifat dana dan (c) Tujuan penelitian

Uhar Suharsaputra

(2012: menyatakan bahwa:

Metode penelitian adalah proses dan mekanisme ilmiah untuk mendapatkan, mengembangkan dan menjawab pengetahuan teori. Perkembangan ilmu pengetahuan mendorong lahirnya paradigma ilmiah dan paradigma penelitian yang variatif tergantung pada basis filosofis ilmu-ilmu, sehingga berakibat pada mekanisme bagaimana penelitian itu dilakukan serta apa yang harus menjadi concern dalam suatu penelitian. 


\section{HASIL PENELITIAN DAN PEMBAHASAN}

\section{Gambaran Umum Lokasi Penelitian}

Perjalanan sejarah lahirnya Kabupaten Buru Selatan secara filosofis dengan berbagai dinamika di tengah peradaban masyarakat Indonesia, Maluku, Buru, dan khususnya Buru Selatan selalu dikenang dan terpatri dalam sanubari anak-anak Fuka Bipolo.

Tahapan demi tahapan perjuangan pembentukan Kabupaten Buru Selatan dimulai sejak 2003. Salah satu instrument advokasi yang dilakukan melalui penyampaian aspirasi dan sikap representatif masyarakat Buru Selatan ke DPRD Provinsi Maluku, dan Gubernur Maluku (kala itu Kantor Gubernur masih menempati kantor Telkom di kawasan Talake-Ambon).

Pada bulan september 2004 hingga April 2005, seluruh stakeholder Pemerintah Desa (Kepala Desa/Dusun, tokoh adat, tokoh agama, tokoh masyarakat, tokoh pemuda dan empat Raja Reheenschaft pada lima kecamatan di Kabupaten Buru Selatan) menyampaikan rekomendasi resmi kepada LPBS untuk disikapi, ditindaklanjuti dan diperjuangkan ke Pemerintah Kabupaten Buru, Pemerintah Provinsi Maluku dan selanjutnya ke Pemerintah Pusat yang intinya Buru Selatan harus menjadi daerah otonom baru di Provinsi Maluku.

\section{Pengembangan Wisata Pantai Wamsoba}

Destinasi Wisata Pantai Wamsoba terletak di Dusun Wamsoba Desa Wali, kecamatan Namrole, Kabupaten Buru Selatan. Pantai Wamsoba juga berada di pusat kota Buru Selatan, Obyek Wisata Wamsoba menjadi salah satu alternatif pilihan tempat berlibur bagi masyarakat kota Namrole dan sekitarnya. berbagai fasilitas penunjang yang dapat dimanfaatkan bagi pengungjung, fasilitas-fasilitas pendukung yang tersedia dalam kawasan objek wiata Wamsoba pun terbuat dari batu-batu alam yang benar- benar alami mulai dari Gazebo, toilet, jalan dan setapak semuanya menggambarkan kondisi alam di Kabupaten Buru Selatan.

Jika perjalan ke Pantai Wamsoba 5 menit dari pusat Kota Namrole satu lagi spot yang bisa dikunjungi saat datang ke Buru Selatan pantai wamsoba, menikmati sore di pingir pantai memang menjadi hal yang menarik, karena pantainya tenang, masih terasa asli karena banyak ditumbuhi pohon besar di sepanjang pantainya, dengan menggunakan sarana transportasi darat Anda dapat menghabiskan waktu libur Anda di lokasi wisata Wamsoba Eco Resort.

\section{SIMPULAN}

Lokasi objek Wisata Pantai Wamsoba yang dibebaskan menjadi Destinasi Pariwisata, berada tepat pada Dusun Wamsoba (permukiman warga), Kecamatan Namrole Kabupaten Buru Selatan. Keunikan Pantai Wamsoba yang tepat berhadapan dengan Laut Banda yang sudah terkenal baik di Nusantara maupun pada skala dunia cukup menarik, di mana pantainya yang memanjang dengan pasir putih yang sangat halus pada bulan pancaroba (musim panas ke musim penghujan) pantai tersebut tertutup dengan batuan kerikil-kerikil yang sangat menarik yang dibawa oleh ombak dan arus laut, selain pemandangan di pantai Wamsoba yang sangat mengesankan, juga pantai tersebut memiliki ombak yang lumayan besar dan menantang, sehingga cocok jika dijadikan tempat favorit untuk berselancar.

Lokasi objek wisata ini tidak terlalu jauh dari sentral kota Kabupaten Buru Selatan,untuk mencapai lokasi objek wisata Pantai Wamsoba hanya membutuhkan waktu 25 menit dari sentral kota Kabupaten Buru Selatan dengan menggunakan kendaraan roda empat (mobil) dan roda dua (motor), namun keadaan jalan memasuki daerah ini masih sangat jelek sehingga harus mendapat perhatian serius. Sarana/prasarana 
belum tersedia sama sekali, dan untuk perencanaan ke depan sangat dibutuhkan untuk membangun MCK bagi warga sekitar, dikarenakan warga pada daerah tersebut rata-rata tidak mempunyai sarana $\mathrm{WC}$ di rumah mereka.

Strategi Pengembangan Destinasi wisata Pantai Wamsoba secara umum mencakup komponen-komponen yang akan berkontribusi pada keberhasilan suatu destinasi wisata secara khusus dan kepariwisataan secara umum, baik meliputi pemasaran, kelembagaan dan industri pariwisata, yaitu sebagai berikut.

1. Menentukan perwilayahan lokasi destinasi pariwisata untuk, lokal, nasional dan internasional dengan melalui pemetaan objek wisata dan membuat peta/jalur kawasan wisata.

2. Pembangunan daya tarik wisata (Atraksi wisata).

3. Prasarana umum, fasilitas umum dan pariwisata yang meliputi prasarana umum (listrik, air, telekomunikasi, pengelolaan limbah), fasilitas umum (keamanan, keuangan perbankan, bsinis, kesehatan, sanitasi.

4. Pemberdayaan masyarakat meliputi sadar wisata dan pengembangan kapasitas masyarakat.

\section{SARAN}

Dari beberapa hal yang diperoleh dari penelitian pengembangan wisata Pantai Wamsoba berbasis kearifan lokal, maka saran-saran yang dapat diajukan adalah sebagai berikut.

1. Pemerintah harus lebih serius dan intens dalam melestarikan serta mengembangkan nilai-nilai kearifan lokal masyarakat.

2. Pemerintah daerah harus lebih sering membuat kegiatan yang bertema pelestarian nilai-nilai kearifan lokal.
3. Meningkatkan sarana transportasi menuju Pantai Wamsoba agar para wisatawan lebih mudah untuk mencapai lokasi wisata.

4. Meningkatkan sarana dan prasarana pendukung agar dapat meningkatkan kenyamanan bagi para wisatawan.

5. Masyarakat harus menjaga dan melestarikan nilai-nilai kearifan lokal.

6. Masyarakat harus berpartisipasi aktif dalam kegiatan pariwisata yang berbasis kearifan lokal.

7. Dibentuknya kelompok-kelompok masyarakat sadar wisata, terutama pada destinasi wisata yang sudah ditentukan atau dijadikan prioritas.

8. Dibentuknya komunitas-komunitas pengrajin atau pembuat souvenir, termasuk komunitas yang memiliki visi kuat tentang wisata Pantai Wamsoba.

9. Dibentuknya jejaring wisata keluar daerah dengan mengoptimalkan para perantau dari Pantai Wamsoba sebagai tenaga promosi wisata Pantai Wamsoba.

\section{DAFTAR RUJUKAN}

Arikunto, Suharsimi, 2013, Prosedur Penelitian Suatu Pendekatan Praktik, Jakarta, PT Rineka Cipta

Creswell, J. W. (2010). Research Design: Pendekatan Kualitatif, Kuantitatif, dan Mixed. Yogyakarta: PT Pustaka Pelajar.

Fenilia Tamaratika, Arief Rosyidie, 2018. Inkorporasi Kearifan Lokal dalam Pengembangan Kawasan Pariwisata Di Lingkungan Pantai. Jurnal Sosioteknologi. Institut Teknologi Bandung. No. 1 Vol 16

I Ketut Mastika, 2018. Pengembangan Ekowisata Berwawasan Kearifan Lokal Di Wilayah Eks Karesidenan Besuki, Jawa Timur. JUMPA Volume 4 No. 2 januari 2018. Universitas Jember

Indrawan, Rully dan Yaniawati, Poppy. 2014. Metode Penelitian: Kuantitatif, dan Campuran untuk Manajemen, 
Pembangunan dan Pendidikan. Bandung. Refika Aditama

Irawan, Koko. 2010. Potensi Objek Wisata Air Terjun Serdang Sebagai Daya Tarik Wisata Di Kabupaten Labuhan Batu Utara. Kertas Karya. Program Pendidikan Non Gelar Pariwisata. Universitas Sumatera Utara.

Iskandar Wiryokusumo Ali, 2013. Dasar-Dasar Pengembangan kurikulum, Jakarta: Bina Aksara

Kodhyat, H. 2003, Kamus Pariwisata dan Perhotelan, PT Pustaka Binawan Presindo

Miles, Matthew B. A. Michael Huberman, Jhonni Saldana. 2014. Qualitative Data Analysis: a metode source book. Third Edition. Arizona State University

Maksimilianus M. Jupir. 2013. Implementasi Kebijakan Pariwisata Berbasis Kearifan Lokal (Studi di Kabupaten Manggarai Barat). Journal of Indonesian Tourism and Development Studies. Vol 1 No. 1

Muhammad Khalis, Teuku Fauzi, Azhar Gani, 2018. Analisis Kearifan Lokal dan Pengembangannya Terhadap Pariwisata Di Kecamatan Sukakarya Kota Sabang. Jurnal Ilmiah Mahasiswa Pertanian Universitas Syahkuala. Vol 3 No. 4 Tahun 2018

Neneng Komariah, Encang Saepudin, Pawit M. Yusup, 2018. Pengembangan Desa Wisata Berbasis Kearifan Lokal. Jurnal Pariwisata Pesona. Volume 03 No. 2, Desember 2018: p 158-174 Program Studi Ilmu Perpustakaan, Universitas Padjadjaran

Noor 2014. Komunikasi Pariwisata: Pemasaran dan Brand Destinasi.. Yogyakarta: Gava Media.

Putra, I Nyoman Darma (ed). 2015. Pariwisata berbasis masyarakat model Bali. Denpasar: Buku Arti bekerja sama dengan Program Studi Magister Kajian Pariwisata, Universitas Udayana.

Sinaga,Supriono.2010.PotensidanPengembangan Objek Wisata Di Kabupaten Tapanuli Tengah. Kertas Karya. Program DIII Pariwisata. Universitas Sumatera Utara.

Sondakh. Angelina 2010. Jendela Pariwisata. Kesaint Blanc. Jakarta
Sunaryo, Bambang. 2013. Kebijakan Pembangunan Destinasi Pariwisata Konsep dan Aplikasinya di Indonesia. Yogyakarta: Gava Media.

Sugiyarto, Rabith Jihan Amaruli, 2018. Pengembangan Pariwisata Berbasis Budaya dan Kearifan Lokal. Jurnal Administrasi Bisnis Volume 7, No. 1, Maret 2018, pp. 45-52 P-ISSN: 22523294 E-ISSN: 2548-4923. Universitas Diponegoro, Semarang, Indonesia

Sugiyono. 2016. Metode Penelitian Kuantitatif Kualitatif dan $R \&$ D. Bandung: Alfabeta

Suryadi, 2010. Pengantar Pariwisata. Jakarta: PT Gramedia Widisarana.

Suryono, Agus. 2010. Dimensi-Dimensi Prima Teori Pembangunan. Malang: UB Press. Suwantoro, Gamal. 1997. Dasar-Dasar Pariwisata. Yogjakarta: Penerbit Andi.

Susanto, 2013. Perencanaan Pengembangan Destinasi Pariwisata. Penerbit UI. Jakarta

Suwantoro, 2007, Pariwisata, Edisi Pertama Kepustakaan Populer Gramedia, Jakarta

Uhar Suharsaputra. 2012. Metode Penelitian Kuantitatif, Kualitatif dan Tindakan. Bandung. Refika Aditama.

Vedho Ardhian Syahputra, 2019. Strategi Pengembangan Kawasan Wisata Pantai Gemah Oleh Dinas Pariwisata Di Desa Keboireng Kecamatan Besuki Kabupaten Tulungagung.

Vitasurya, V. R. (2016). Wisdom for Sustainable Development of Rural Tourism, Case on Kalibiru and Lopati Village, Province of Daerah Istimewa Yogyakarta. Procedia (Social and Behavioral Sciences), 97108.

\section{Peraturan Perundang-Undangan}

Undang-Undang Dasar Tahun 1945 Amendemen ke-4

Undang Undang No. 10/2009 tentang Kepariwisataan

Undang-Undang No. 23 Tahun 2014 tentang Pemerintahan Daerah 
Undang-Undang No. 18 Tahun 2002 tentang Sistem Nasional Penelitian, Pengembangan, dan Penerapan Ilmu Pengetahuan dan Teknologi

Peraturan Daerah Kabupaten Buru Selatan No. 03 Tahun 2013 tentang Rencana Pembangunan Jangka Panjang Daerah Kabupaten Buru Selatan Tahun 2009. 2029

\section{Sumber Lainnya}

Kemenpar, 2019. Strategi Pengembangan Kepariwisataan, Puslitbang Kemenpar. Jakarta

Rencana Strategis (Renstra) Dinas Kebudayaan dan Pariwisata Kab Buru Selatan Tahun 2019 